\title{
Effect of Inlet and Geometrical Parameters on the Melting of PCM Capsules of Elliptical Cross Section
}

\author{
Mohamed A. Sultan ${ }^{1 *}$, Hesham M. Mustafa ${ }^{2}$, Emad A. El-Negiry ${ }^{3}$ \\ and Ali M. El-Boz ${ }^{3}$
}

\author{
${ }^{I}$ Mechanical. Eng. Dept, Future Institute of Engineering and Technology, Talkha, Egypt. \\ ${ }^{2}$ Mechanical Eng. Dept., Higher Technological Institute, $10^{\text {th }}$ of Ramadan \\ ${ }^{3}$ Mechanical Power Eng. Dept., Faculty of Eng, Mansoura University, Mansoura, Egypt. \\ *(Corresponding author:sultanaan@gmail.com)
}

\begin{abstract}
This paper focuses on the melting of phase change material capsulated in the elliptical cross-section horizontal cylinder under convective boundary conditions. Different parameters are discussed, namely, the HTF inlet temperature and velocity and the axes ratio of the capsule cross-section. The effect of HTF inlet temperature, inlet velocity, and the capsule axes ratio was studied using the CFD software FLUENT 6.3.26. A comparison between the numerical and experimental results was made for the system. The experimental results matched well with the heat transfer model. It is shown that the inlet temperature of the heat transfer fluid (HTF) has a great effect on the process of paraffin wax melting. The increase of HTF inlet temperature increases the PCM liquid fraction at constant charging time and decreases at the same time the total time of the capsulated paraffin wax melting. The geometry of the capsule crosssection represented by its axes ratio has a sensible effect on the process of paraffin wax melting. Increasing the axes ratio of the capsule, i.e. elongated the capsule in the perpendicular direction of flow increasing the PCM liquid fraction at constant charging time and decreases the total time of the capsulated paraffin wax melting. The increase of HTF inlet velocity has a weak effect on the process of paraffin wax melting in the inlet velocity range $0.003-0.012 \mathrm{~m} / \mathrm{s}$.
\end{abstract}

Keywords: Encapsulated, PCM, Heat transfer, Melting time, Axes ratio, Elliptical cross-section.

\section{Introduction}

Because of their thermal properties, phase change materials are extremely utilized in thermal systems. These materials have the ability to absorb and release great amounts of heat with a slight temperature change and density (has a high rate of fusion). This heat is called latent heat of fusion of phase change material (PCM). PCM is utilized in many disciplines for latent heat storage; for example, solar based thermal energy [1] in buildings heating [2], spacecraft heat, and pumps [3]. Because of its low thermal conductivity, the usage of PCM has been limited [4].

Research has been carried out on phase change materials with an implementation in thermal systems. Enclosures with diverse shapes and sizes had been investigated experimentally and analytically. Numerous researches were carried out to examine the melting and solidification of PCM filled inside cylindrical, tubular, rectangular and spherical cross-section capsules are epitomized in the next paragraphs.
It is reported that the capsules geometry had a great impact on the heat transfer features. Wei et al. [5] carried out experimental and numerical studies on a number of geometries of PCMs capsules, such as, plate, sphere, tube and cylinder to develop the rate of heat transfer. It was concluded that the spherical capsule usage increased the heat transfer amount. The rate of heat transfer for other shapes increased in the sequence of tube, plate and cylinder. Siva et al. [6] analyzed different shapes of constant volume filled with PCM, and reported that the cylinder had an encapsulation best than the sphere. The cylinder surface area was $38 \%$ higher than that for the sphere, which caused $47 \%$ decrease in the solidification total time. To decrease the solidification time the cylinder selected dimensions were such that the radius is not large enough. So, the shape selection of the capsules played a great effect on the thermal energy storage (TES) systems.

In spite of a lot of numerical and experimental searches were dedicated to a PCM melting for various geometric shapes in convection field, a specific interest was disposed to the melting 
process inside a cylinder, placed in horizontal position as a TES model [7-9]. Based on the Boussinesq approximation, many analytical and numerical investigations were accomplished as attempts for melting phenomenon modeling in a horizontal cylinder of circular cross section [1014]. Saitoh and Hirose [10] offered experiments to indicate the concaved border at the lower portion of liquid/solid border over melting. Experimental studies were conducted by Rieger et al. [11], Ho and Viskanta [12], and Yoo and Ro [13], on the development of a liquid-solid interface through the melting of PCM contained inside a horizontal cylinder. A concaved liquid-solid interface was shown experimentally and numerically at the lower portion of solid phase. The unconstrained PCM melting inside a horizontal cylinder under isothermal condition was studied numerically by Prasad and Sengupta [14]. The study estimated the temporally, irregular shape of the solid-liquid boundary. The study proved that the solid PCM moving downward as a result of the difference in densities between liquid and solid, and the liquid phase free convection.

Agyenim et al. [15] stated that rectangular and cylindrical models were the enclosure shapes that usually used to augment the heat transfer between the heat transfer fluid and the PCM.

A thermal model was developed by Palanisamy and Niyas [16] to perform comparisons between different geometrical shapes of latent heat storage (LHS)/ sensible heat storage (SHS) capsules. The numerical results showed that, the cylindrical enclosure produced melting time lesser than that of the spherical one having the same mass of storage media. This was because the distance from the capsule periphery to its center was lesser in cylindrical shape than in spherical one.It was found that the charging time increased with the decrease of axes ratio for the cylindrical configuration.

Different methods for measuring the phase change have been used in experiments using PCM. Jones et al. [17] used a photographically method to capture the change in phase and determine the location of its boundary using digital image processing techniques. Other methods include weighing the PCM periodically [18-19] or measuring the change in density of the PCM [20].

Sultan et al. [21] investigated the melting and solidification of elliptical cross section capsules filled with Paraffin wax with capsules axes ratio less than one. The authors discussed the effect of HTF inlet velocity and temperature besides the axes ratio.

The aim of this study is to discuss the melting processes of PCM elliptical cross-sections cylindrical capsules in centimeter-scale having axes ratio higher than one with a convective boundary condition. Nominating the elliptical cross section is due to the increase of its peripheral with the change in the section axes ratio and consequently increasing the surface area of the capsule under constant PCM mass. Effect of axes ratio, inlet temperature and inlet velocity of heat transfer (HTF) on melting time and liquid fraction of molten paraffin will be investigated.

\section{Experimental test rig}

An experimental setup was designed and manufactured at the air conditioning laboratory Mechanical Power Engineering Department, Faculty of Engineering, Mansoura University. This setup was built to validate the numerical solution for the melting of phase change materials (PCMs) using the Fluent Computational Fluid Dynamics (CFD) software.

The test rig consists, as shown in Fig. 1, of a cube tank (10) made of galvanized steel sheet with a diameter of $30 \mathrm{~cm}$ and $30 \mathrm{~cm}$ height. The tank is used to supply the test section with hot water (11) at different temperatures. The tank is insulated with glass wool insulation to decrease the heat loss from hot water in the tank. The tank is equipped with a $1 \mathrm{~kW}$ electric heater (12) connected to the electrical main supply with a voltage cutoff adapter that provides a voltage variation from 0 to $220 \mathrm{~V}$ to adjust the water temperature in the tank at a predefined temperature. The reservoir is equipped with a small 100-Watt pump (8) connected to the tank bottom to supply the test section with hot water required to heat the capsule at different velocities using valve (7) which regulates the water discharge rate to the test section (1).

The test section (1) is a rectangular cross section channel of $8 \mathrm{~cm}$ by $10 \mathrm{~cm}$ cross section and $15 \mathrm{~cm}$ height. Hot water is brought to it by $1 / 2$ " pipe diameter (4) connected to the bottom of the channel through the pump (8). To drain the water into the hot water tank, a hole of $1 / 2$ " diameter is used and a tube (9) of the same diameter is connected to one side near the top of the channel to return the water back to the hot water tank. The inlet water temperature is measured using the thermometer (3). The Pyrex glass capsule (2) filled with PCM is placed in a horizontal position using a $1 \mathrm{~mm}$ diameter wire carrier. It has an elliptical cross section, with axes dimensions of 6.2 and 2.6 $\mathrm{cm}$. It is filled with the molten paraffin, then left to cool and closed with its lid.

To facilitate the vision and image of the capsule, the test section was made from Plexiglass. In order to measure the average temperature of the water before entering the channel, a thermometer (3) is fixed inside the channel (1). The rate of hot water passing through the test section is measured by the amount of water collected at a given time during the experiment. The camera of a mobile model Samsung Galaxy j2 is used to take the photos of the capsule during melting process. 


\section{Numerical Model}

The thermal model describing this system is based on the following assumptions: (1) the fluid flow is incompressible, laminar and the flow rate is steady with time; (2) one dimensional heat transfer; (3) there is no heat lost to the surroundings; (4) PCM and HTF thermo-physical properties are not dependent on temperature; (5) the convection influences the PCM melting and is taken into consideration in the energy equation through the use of an effective thermal conductivity $\mathrm{k}_{\mathrm{eff}}$; and (6) the heat is transferred between the HTF and the exposed surface of the capsules by convection due to the temperature difference between them.

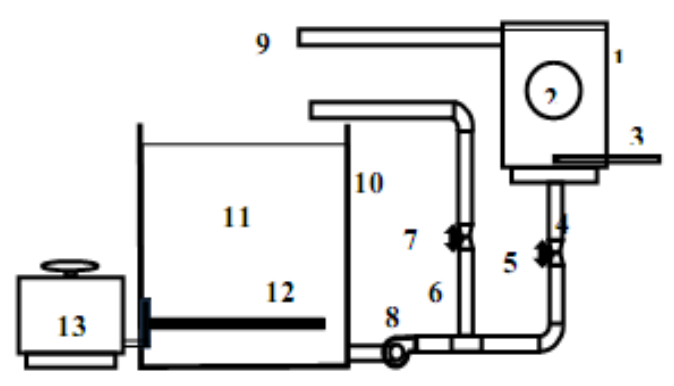

1- Test section 2- PCM Capsule 3-Thermometer 4- Inlet connection 5-Supply valve 6-Bypass connection 7- Bypass valve 8- Water pump 9Outlet connection 10- Water tank 11- Hot water 12- Electric heater 13-Electric transformer.

Figure 1- Layout of the test rig

capsule and exit from the top of the tank, while the PCM is a commercial grade paraffin wax. The latent heat of fusion, phase change temperature and other thermo-physical properties are shown in Table 1. During the PCM melting (or charging process), the inlet HTF temperature is maintained constant and higher than the melting temperature of the PCM, and velocity also is kept constant.

Figure 2 shows the representation of the thermal storage system considered for the numerical analysis. An insulated duct of height 0.3 $\mathrm{m}$, cross section of width twice the ellipse's horizontal axis, and a length of $1 \mathrm{~m}$ is used. The PCM capsules have horizontal and vertical axes laying with its centre line on the centerline of the duct.

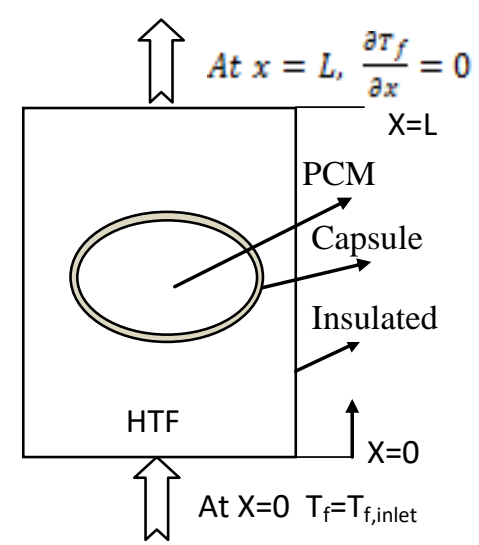

Figure 2- Thermal storage model for configuration

The water as HTF enter from the bottom and flows around the elliptical cross sectional capsule and exit from the top of the tank, while the PCM is a commercial grade paraffin wax. The latent heat of fusion, phase change temperature and other thermo-physical properties are shown in Table 1. During the PCM melting (or charging process), the inlet HTF temperature is maintained constant and higher than the melting temperature of the PCM, and velocity also is kept constant.

The CFD software Ansys-Fluent 2019 R2 is used to carry out the numerical solution to solve melting model and the energy equation in three steps. Firstly, the geometry is created with Gambit software and the cylindrical space is treated as fluid (PCM). Secondly, to maintain minimum deviation, mesh is created by dividing the computational domain into different mesh elements. The convergence criterion of $10^{-6}$ is used for the studied case. Thirdly, the physical parameters for 2dimension axisymmetric model (PCM) used in this study. The stored energy is in two forms latent and sensible heat. Sensible heat dominates on regions where the temperature of PCM is lower than $329 \mathrm{~K}$ or higher than $331 \mathrm{~K}$ and in between them the latent heat is predominated. The thermo physical properties of paraffin wax showed in Table (1).

Table 1- Thermo physical properties of paraffin wax.

\begin{tabular}{|l|l|l|}
\hline Property & Solid & Liquid \\
\hline $\begin{array}{l}\text { Thermal conductivity, } \\
\text { W/m.K }\end{array}$ & 0.15 & 0.147 \\
\hline Heat capacity, kJ/kg.K & 2.354 & 2.44 \\
\hline Density, kg/m ${ }^{3}$ & 890 & 712 \\
\hline Dynamic viscosity, Pa.s & ------ & 0.0052 \\
\hline $\begin{array}{l}\text { Coefficient of thermal } \\
\text { expansion, } \mathrm{K}^{-1}\end{array}$ & ------ & 0.000714 \\
\hline Saturation temperature, K & 329 & 331 \\
\hline Latent heat, $\mathrm{kJ} / \mathrm{kg}$ & 259 & \\
\hline
\end{tabular}



and Geometrical Parameters on the Meltingof PCM Capsules of Elliptical Cross Section”

\section{Governing Equations}

Voller and Prakash [21] and Voller and Swaminathan [22] formulated the enthalpyporosity model to simulate the process of phase change. The solid-liquid mushy zone in this model was considered as a porous medium where its porosity was equal to the liquid fraction of the molten PCM. The liquid fraction, $\lambda$, was specified as the volume ratio of the molten PCM to its total volume. The porosity and liquid fraction is ranged from 0 at the beginning of the melting process to 1 at the complete melting of PCM. Based on the enthalpy equilibrium the liquid fraction is calculated at each step. The porosity of the material becomes zero when it has fully solidified in the cell that makes the velocities equal to zero. This attitude of the interface as per Darcy's law damping mechanism is contained in the momentum equation as a source term due to the phase change effect on natural convection.

The summation of the sensible enthalpy, h, and latent heat, $\Delta \mathrm{H}$, is the total enthalpy of the material:

$$
\mathrm{H}=\mathrm{h}+\Delta \mathrm{H}
$$

In terms of the material latent heat $\mathrm{L}$, the heat of fusion can be written as:

$$
\Delta \mathrm{H}=\lambda * \mathrm{~L}
$$

where $\Delta \mathrm{H}$ varies from $\mathrm{L}$ (liquid) to zero (solid), therefore, one can define the liquid fraction, $\lambda$ as:

$$
\begin{gathered}
\lambda=\frac{\Delta \mathrm{H}}{\mathrm{L}}=0 \text { for } \mathrm{T}<\mathrm{T}_{\text {solid }} \\
\lambda=\frac{\Delta \mathrm{H}}{\mathrm{L}}=1 \text { for } \mathrm{T}>\mathrm{T}_{\text {liquid }} \\
\lambda=\frac{\Delta \mathrm{H}}{\mathrm{L}}=\frac{\mathrm{T}-\mathrm{T}_{\text {solid }}}{\mathrm{T}_{\text {liquid }}-\mathrm{T}_{\text {solid }}} \\
\text { for } \mathrm{T}_{\text {solid }} \leq \mathrm{T} \leq \mathrm{T}_{\text {liquid }}
\end{gathered}
$$

Energy equation

The energy equation for the melting model is written as, [22]:

$$
\frac{\partial}{\partial t}(\rho \mathrm{H})+\nabla \cdot(\rho \overrightarrow{\mathrm{V}} \mathrm{H})=\nabla \cdot(\mathrm{k} \nabla \mathrm{T})+\mathrm{s}
$$

The solution for temperature is principally an iterative between the energy equation and the liquid fraction equation.

Continuity equation

$$
\nabla \cdot \vec{V}=0
$$

Momentum equation

The mushy zone is treated as a porous medium in the enthalpy-porosity technique, and in momentum equation, the porosity in every cell is taken equal to the cell liquid fraction. The porosity in fully solidified regions is equal to zero, which vanish the velocities in these regions. The damping term $\vec{S}$ of the momentum sink that is added to the momentum equation due to the phase change effect on convection is, [22]:

$$
\overrightarrow{\mathrm{S}}=-\frac{\left(1-\lambda^{2}\right)}{\left(\lambda^{3}-\varepsilon\right)} A_{m u s h} \overrightarrow{\mathrm{V}}
$$

where $\lambda$ is the liquid fraction, $\varepsilon$ is the mushy zone constant, it is a small number (0.001) to avoid division by zero.

The momentum equation for the melting problem is written as [23]:

$$
\begin{array}{r}
\frac{\partial \overrightarrow{\mathrm{V}}}{\partial \mathrm{t}}+\overrightarrow{\mathrm{V}} \cdot \nabla \overrightarrow{\mathrm{V}}=\frac{1}{\rho}\left(-\nabla P+\mu \nabla^{2} \overrightarrow{\mathrm{V}}+\right. \\
\left.\rho \beta \vec{g}\left(T-T_{\text {ref }}\right)\right)+\vec{S}
\end{array}
$$

The elliptical section is drawn in the GAMBIT software program so that the axes ratio can be changed to any desired value, including an axes ratio of 1 which represents the circular crosssection.

\section{Results and Discussion}

Firstly, the mesh independence study is performed to determine the suitable grid size followed by a comparison between the experimental and numerical results to validate the numerical solution.

\subsection{Grid independence study}

To solve the numerical model a free triangular mesh is chosen. In order to examine the numerical results dependent on the mesh size a simulation is run on a circular cylindrical capsule of $4 \mathrm{~cm}$ diameter and $6 \mathrm{~cm}$ length. The capsule initial temperature is equal to $300 \mathrm{~K}$, while at any time higher than zero, the heat transfer fluid is at $343 \mathrm{~K}$. The capsule liquid fraction and mean temperature are compared for different mesh sizes and it is shown from Figs. 3 and 4 that mesh size of 0.00035 $\mathrm{m}$ can be used to solve the numerical model accurately.

Similarly, the grid independence study is carried out for other configurations of the elliptical capsules. Time step used in the analysis is $0.5 \mathrm{~s}$ throughout all models. 


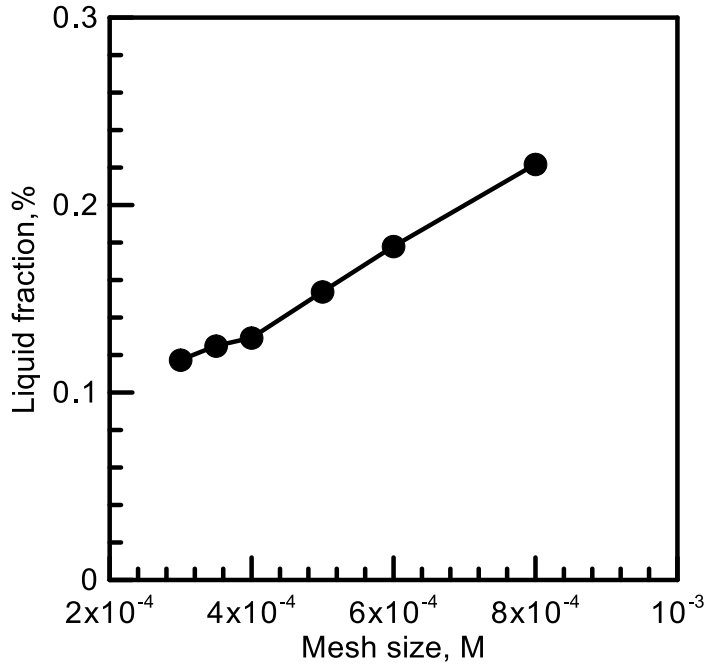

Figure 3- Effect of mesh size on PCM liquid fraction at constant HTF inlet temperature of $343 \mathrm{~K}$ and velocity of $0.003 \mathrm{~m} / \mathrm{s}$

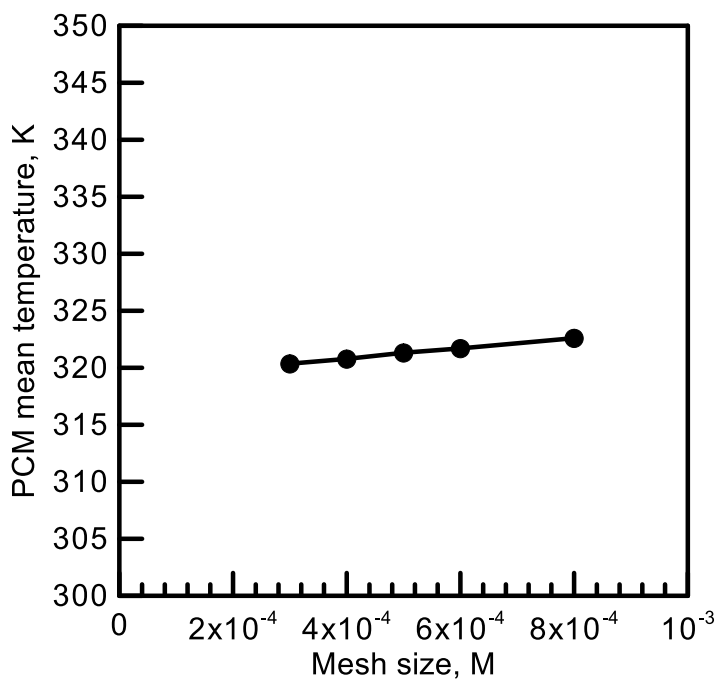

Figure 4- Effect of mesh size on PCM mean temperature at constant $\mathrm{HTF}$ inlet temperature of $343 \mathrm{~K}$ and velocity of $0.003 \mathrm{~m} / \mathrm{s}$

\subsection{Validation of numerical results}

A comparison between the experimental results of the elliptical cross section capsule of $A_{r}=2.6$ with the numerical results of a capsule of the same shape and dimensions, obtained from the numerical model was made.

Fig. 5 illustrates as a contour the variation of the liquid fraction of PCM melting with the pictures that were captured during the experiments for HTF initial velocity and temperature of 0.003 $\mathrm{m} / \mathrm{s}$ and $340 \mathrm{~K}$, respectively. It is shown from the figure that there is a fair agreement between the experimental and numerical results and the shape of molten and solid paraffin.

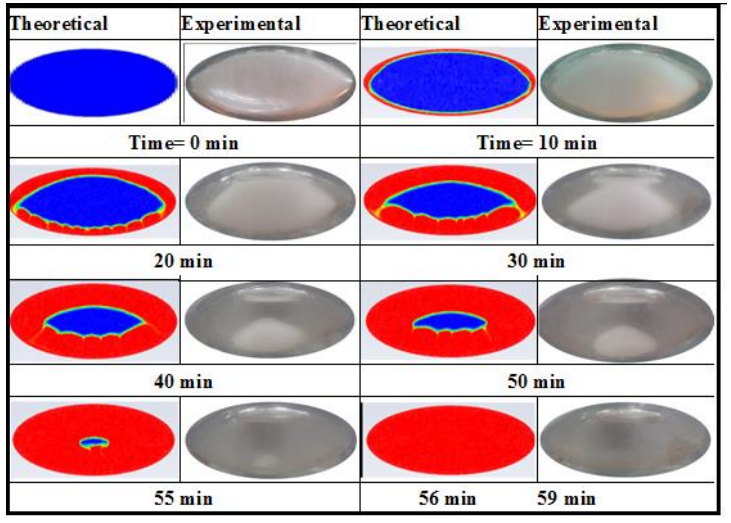

Figure 5- Comparison between liquid fraction contours and camera photos of paraffin wax elliptical cross sectional capsule

The experimental results of liquid fraction are calculated from the camera photos using two programs, the first of which is an online photo editor called "Photopea" at www.photopea.com which is used to eliminate the elliptical capsule from the photo. The second program is online "Image Color Extract Tool" at www.coolphptools.com/color_extract\#demo wich enables the determination of the percentage of the solid "white color" and the liquid "gray color".

Fig. 6 shows the relation between liquid fraction and time for both experimental and theoretical results for an oblate capsule of $\mathrm{A}_{\mathrm{r}}=2.61$ at HTF inlet temperature of $340 \mathrm{~K}$ and a velocity of $0.003 \mathrm{~m} / \mathrm{s}$. It is seen from the figure that the two results are in fair agreement.

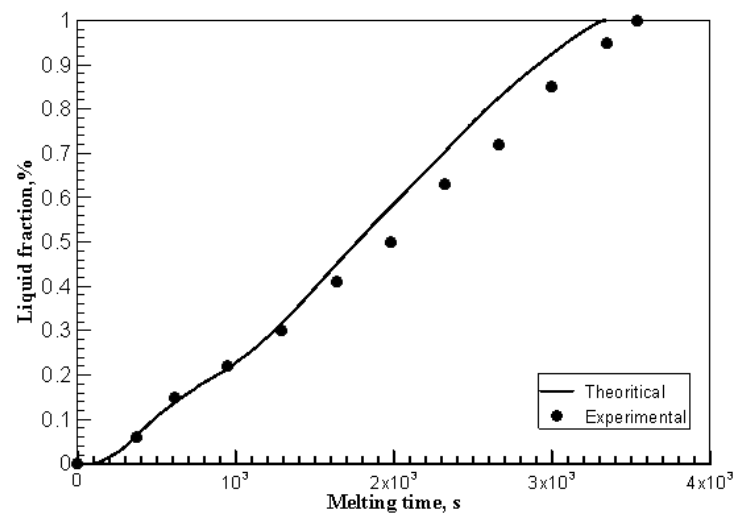

Figure 6- Comparison between experimental and theoretical PCM liquid fraction results of capsule with axes ratio 2.61 at HTF inlet temperature of $340 \mathrm{~K}$ and velocity of $0.003 \mathrm{~m} / \mathrm{s}$

The fair agreement between the numerical and experimental results ensures the numerical model validity of and the accuracy of different paraffin wax thermal properties. 


\subsection{Effect of discussed parameters}

In the following section, the effect of the axes ratio of the elliptical cross section-capsule, the inlet temperature and velocity of the heat transfer fluid (HTF) will be discussed.

\section{Effect of axes ratio}

Figs. 7-9 show the Effect of charging time and capsule axes ratios on PCM liquid fraction, stored energy and mean temperature, at constant HTF inlet velocity and temperature of $0.003 \mathrm{~m} / \mathrm{s}$ and 343 $\mathrm{K}$, respectively. The figures show that liquid fraction, stored energy and mean temperature of paraffin wax increase with charging time at the same value of the capsule axes ratio. The figures also show that the axes ratio significantly affects the liquid fraction, stored energy and mean temperature of paraffin wax at the same charging time.

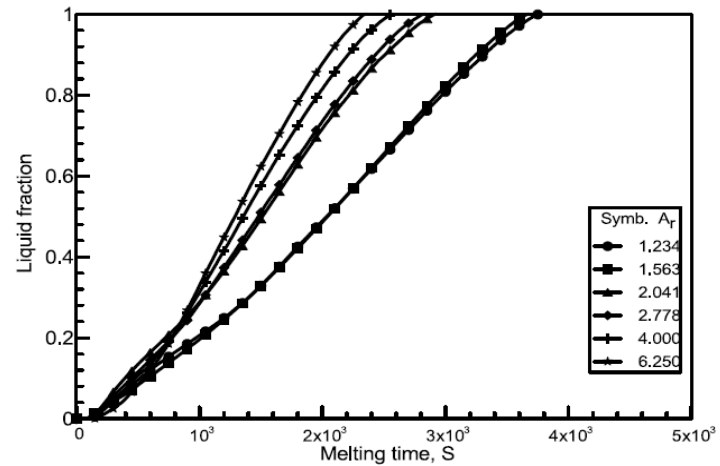

Figure 7- Effect of capsule axes ratio $\mathrm{A}_{\mathrm{r}}$ on PCM liquid fraction at constant $\mathrm{HTF}$ inlet temperature of $343 \mathrm{~K}$ and velocity of $0.003 \mathrm{~m} / \mathrm{s}$

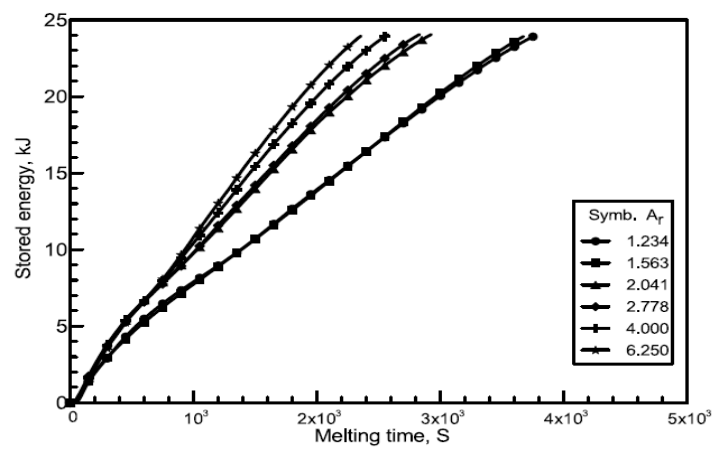

Figure 8- Effect of capsule axes ratio $A_{r}$ on stored energy at HTF inlet temperature of $343 \mathrm{~K}$ and velocity of $0.003 \mathrm{~m} / \mathrm{s}$

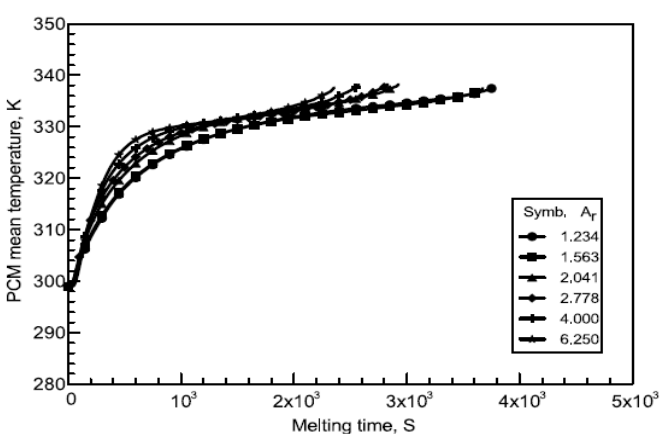

Figure 9. Effect of capsule axes ratio $\mathrm{A}_{\mathrm{r}}$ on PCM mean temperature at constant HTF inlet temperature of $343 \mathrm{~K}$ and velocity of $0.003 \mathrm{~m} / \mathrm{s}$

The relationship between the total melting time and capsule axes ratio is shown in Fig. 10 for HTF inlet temperature and velocity of $343 \mathrm{~K}$ and 0.003 $\mathrm{m} / \mathrm{s}$, respectively. The figure clearly indicates that the total melting time decreases with the increase in capsule axes ratio. This because the increase in capsule axes ratio increases the capsule surface area and consequently increases the heat transferred to it. Although the separation angle decreases with the increase in axes ratio, as shown in Fig. 11, but the surface area of the capsule before separation increases and consequently the amount of heat transfer increases.

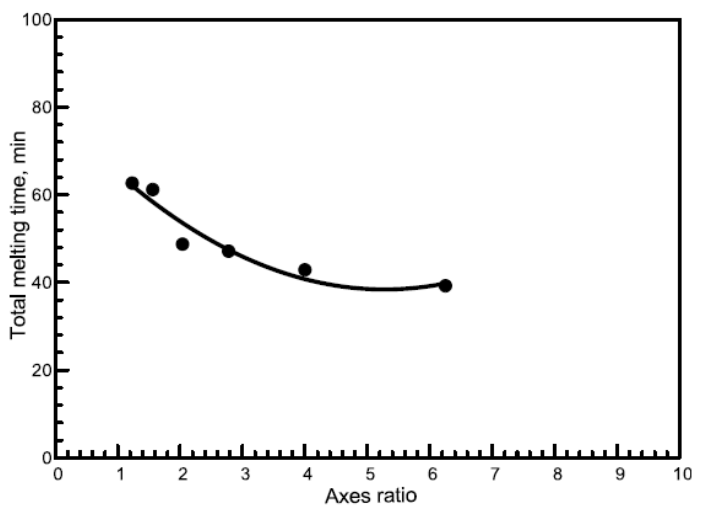

Figure 10- Effect of capsule axes ratio $\mathrm{A}_{\mathrm{r}}$ on PCM total melting time at HTF inlet temperature of 343 $\mathrm{K}$ and velocity of $0.003 \mathrm{~m} / \mathrm{s}$. 


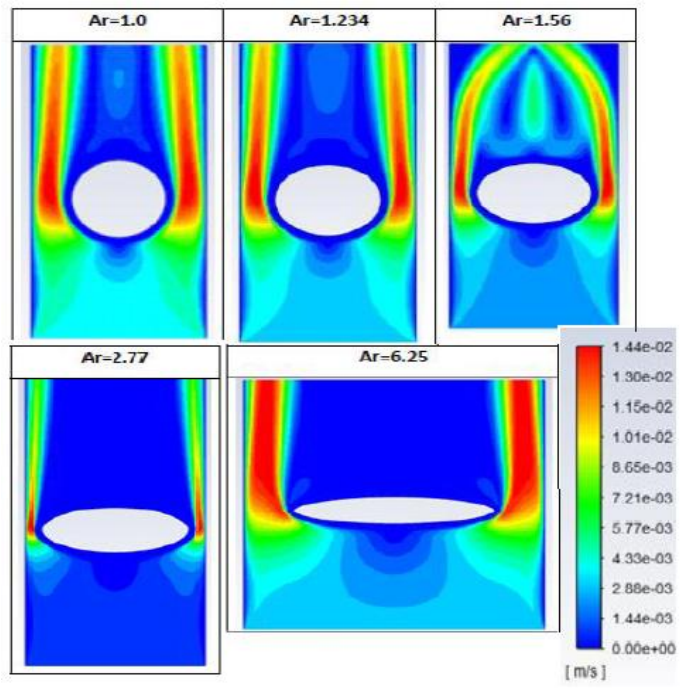

Figure 11- Velocity contours for different aspect ratios

\section{Effect of HTF inlet temperature}

The variations of PCM liquid fraction, stored energy and mean temperature with charging time and HTF inlet temperature are plotted in Figs. 1214 , for a capsule with axes ratio of 1.234 under a HTF inlet velocity of $0.003 \mathrm{~m} / \mathrm{s}$. The figures show that the higher the HTF inlet temperature the higher the liquid fraction, stored energy and mean temperature of paraffin wax at the same charging time. The figures also show that the liquid fraction, stored energy and mean temperature of paraffin wax increase with charging time at the same HTF inlet temperature.

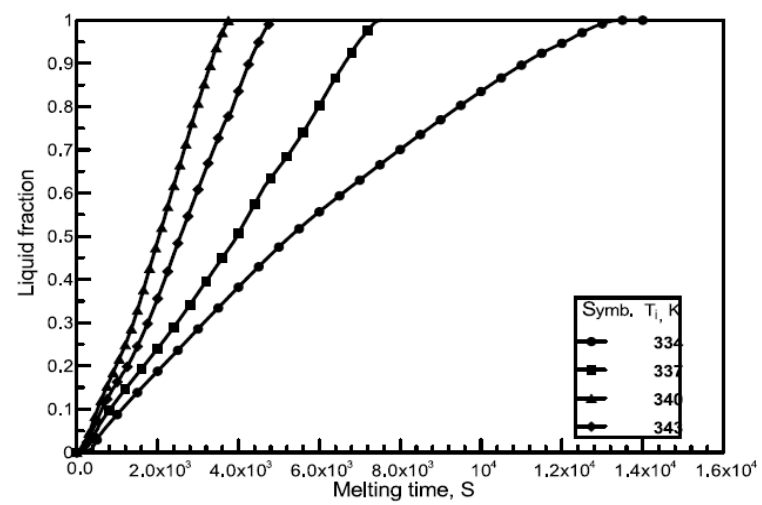

Figure 12- Effect of HTF inlet temperature on PCM liquid fraction at constant aspect ratio of 1.234 and $\mathrm{HTF}$ inlet velocity of $0.003 \mathrm{~m} / \mathrm{s}$

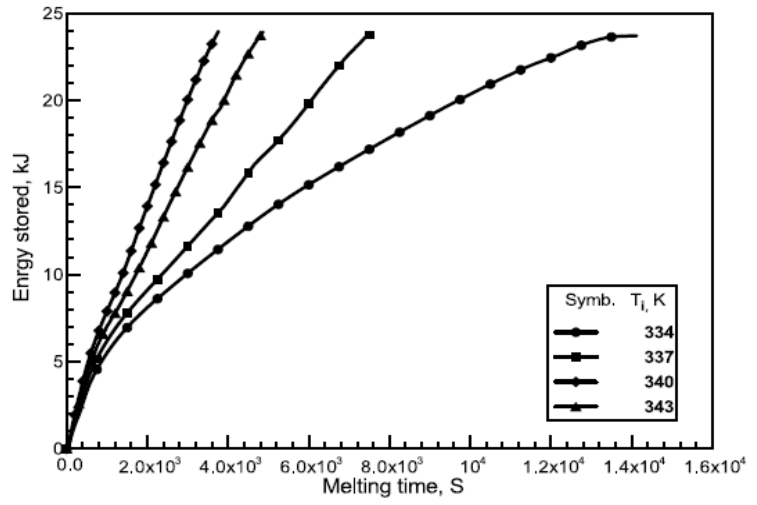

FIgure 13- Effect of HTF inlet temperature on PCM energy stored at constant aspect ratio of 1.234 and HTF inlet velocity of $0.003 \mathrm{~m} / \mathrm{s}$

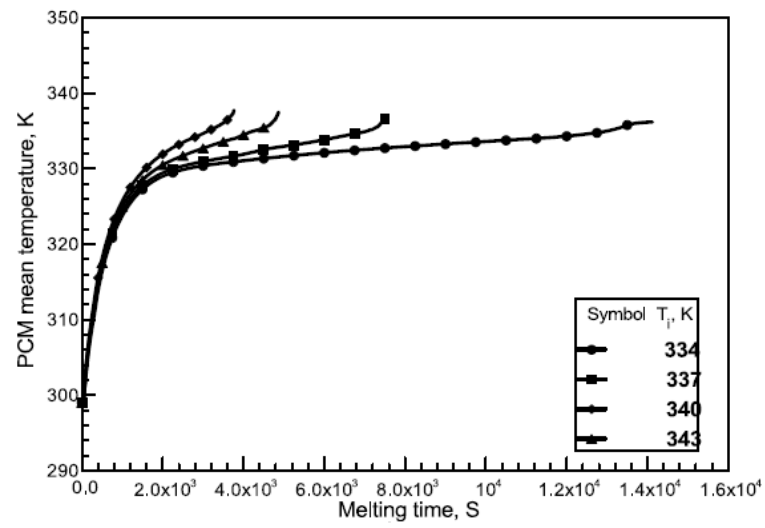

FIGURE 14- Effect of HTF inlet temperature on PCM mean temperature at constant aspect ratio of 1.234 and HTF inlet velocity of $0.003 \mathrm{~m} / \mathrm{s}$

Figure 15 shows the effect of HTF inlet temperature on the total melting time for HTF inlet velocity of $0.003 \mathrm{~m} / \mathrm{s}$ and axes ratio of 1.234 . It is clear from the figure that the total melting time decreases with the increase of HTF inlet temperature. This is due to the increase in heat transferred to the capsule as a result of the increase in temperature difference between the HTF and the PCM inside the capsules.

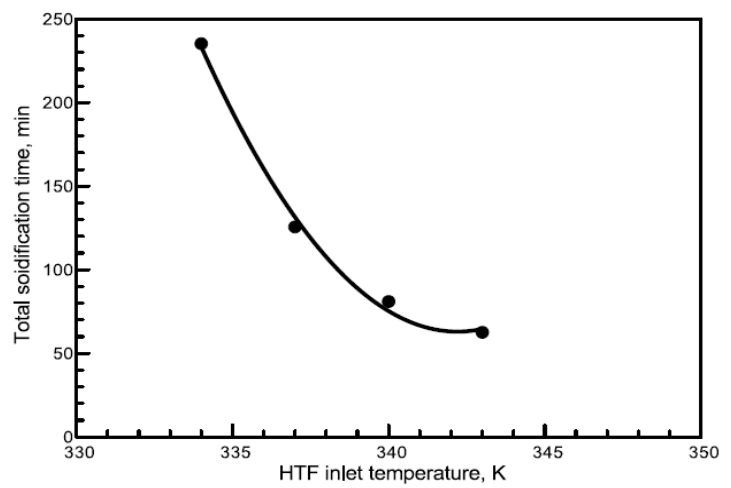

Figure 15- Effect of HTF inlet temperature on PCM total solidification time at capsule aspect ratio of 1.234 and velocity of $0.003 \mathrm{~m} / \mathrm{s}$ 

and Geometrical Parameters on the Meltingof PCM Capsules of Elliptical Cross Section"

\section{Effect of HTF inlet velocity}

PCM mean temperature and liquid fraction as a function of melting time are plotted in Figs. 16-17. The axes ratio and HTF inlet temperature are kept constant at 1.234 and $343 \mathrm{~K}$, respectively, while the HTF inlet velocity is ranged from 0.003 to 0.012 $\mathrm{m} / \mathrm{s}$. The figures indicate that the liquid fraction and mean temperature of paraffin wax increase with charging time at the same HTF inlet velocity. It is also shown from the figures that the liquid fraction slightly increases whilethe mean temperature of paraffin wax is kept nearly constant with HTF inlet velocity at the same charging time.

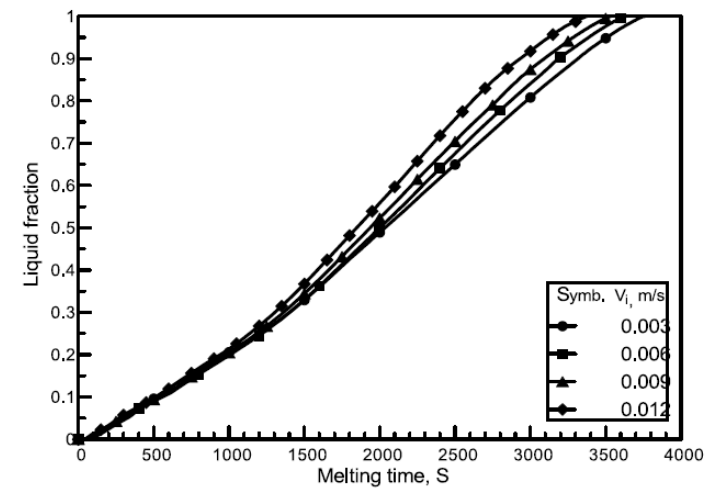

Figure 16- Effect of HTF inlet temperature on PCM liquid fraction at constant axes ratio of 1.234 and HTF inlet temperature of $343 \mathrm{~K}$.

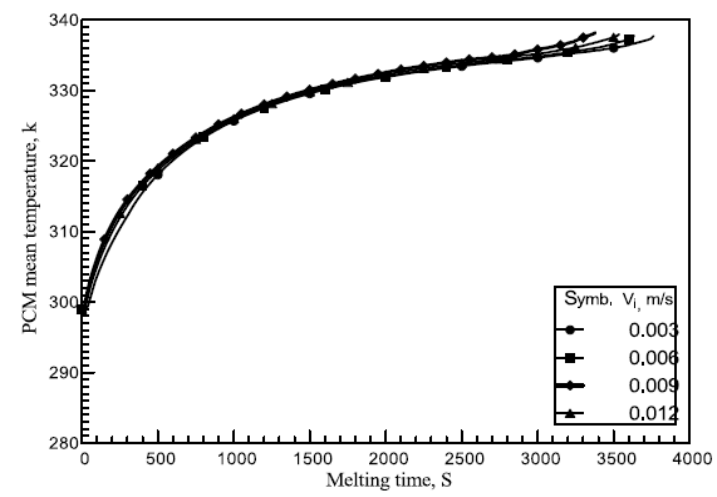

Figure 17- Effect of HTF inlet temperature on PCM mean temperature at constant axes ratio of 1.234 and HTF inlet temperature of $343 \mathrm{~K}$

Figure 18 illustrates the relationship between total melting time and HTF inlet velocity for axes ratio of 1.234 and HTF inlet temperature of $343 \mathrm{~K}$. It is seen from the figure that the total melting time slightly increases with the decrease of HTF inlet velocity. This is because increasing the HTF inlet velocity decreases the heat transfer resistance by only a small value while the other thermal resistances of PCM is still very small compared to it.

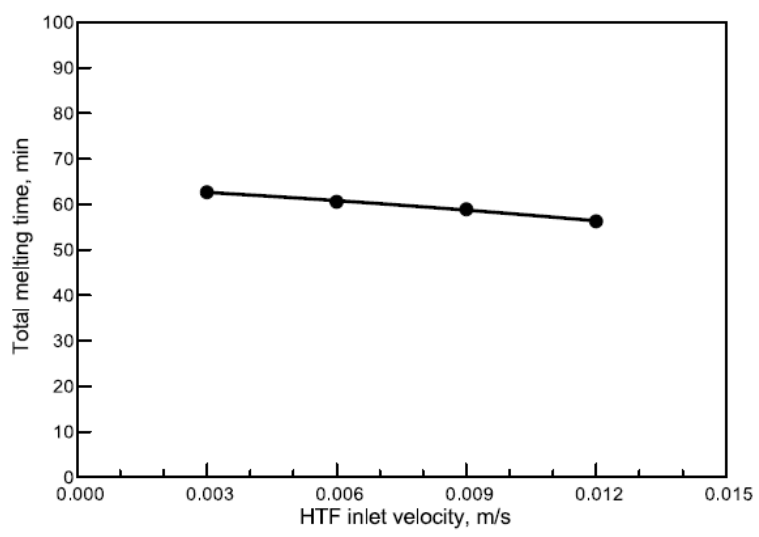

Figure 18. Effect of HTF inlet velocity on PCM total melting time at capsule aspect ratio of 1.234 and HTF inlet temperature of $343 \mathrm{~K}$.

\section{Conclusions}

From the above-discussed results of the process of paraffin wax melting inside elliptical crosssectional capsules of different axes ratio under HTF flowing with different inlet velocities and temperatures, the following conclusions are made:

1- The increase of HTF inlet velocity has a weak effect on the paraffin wax melting time in the

2- The geometry of the capsule cross-section represented by its axes ratio has a remarkable effect on the process of paraffin wax melting. Increasing the axes ratio of the capsule, i.e. elongated the capsule in the perpendicular direction of flow, increases the PCM liquid fraction and decreases the total time of melting of the capsulated paraffin wax

3-The inlet temperature of the heat transfer fluid (HTF) has a great effect on the process of paraffin wax melting. The increase of HTF inlet temperatures increases the PCM liquid fraction and decreases at the same time the total time of melting of the capsulated paraffin wax. 

and Geometrical Parameters on the Meltingof PCM Capsules of Elliptical Cross Section”

\section{Nomenclature}

A: Surface area of test tube, $\mathrm{m}^{2}$

$\mathrm{C}_{\mathrm{p}}$ : Specific heat at constant pressure, J/kg.K

D: Diameter, $m$

E: Total energy stored, $\mathrm{kJ} / \mathrm{kg}$

$\mathrm{g}$ : Acceleration of gravity, $\mathrm{m} / \mathrm{sec}^{2}$

$\mathrm{H}$ : Total enthalpy, $\mathrm{J} / \mathrm{kg}$

$\mathrm{h}$ : Sensible enthalpy, $\mathrm{J} / \mathrm{kg}$

$\mathrm{k}$ : Thermal conductivity, W/m.K

$\mathrm{L}$ : Latent heat of fusion, $\mathrm{J} / \mathrm{kg}$

Q: Heat transfer rate, $\mathrm{W}$

q: Heat flux, W/m ${ }^{2}$

$\overrightarrow{\mathbf{S}}$ : Source term

$\mathrm{t}$ : Time, $\mathrm{s}$

\section{References}

[1] V. Kapsalis, and D. Karamanis, "Solar thermal energy storage and heat pumps with

[2] B. Zalba, J.M. Marin, L.F. Cabeza, and H. Mehling, "Review on thermal energy storage with phase change: materials, heat transfer analysis and applications," Appl. Therm. Eng. 23(2003) 251-283.

[3] A. Sharma, V.V. Tyagi, C.R. Chen, and D. Buddhi, "Review on thermal energy storage with phase change materials and applications," Renewable and Sustainable Energy Reviews 13(2009) 318-345.

[4] J. Yang, L. Yang, C. Xu, and X. Du, "Experimental study on enhancement of thermal energy storage with phase-change material," Applied Energy 169(C)(2016) 164-176.

[5] J. Wei, Y. Kawaguchi, S. Hirano, and H. Takeuchi, "Study on a PCM heat storage system for rapid heat supply," Appl. Therm. Eng. 25(2005) 2903-2920.

[6] K. Siva, M.X. Lawrence, G.R.Kumaresh, P.Rajagopalan, and H.Santhanam, "Experimental and numerical investigation of phase change materials with finned encapsulation for energy efficient buildings," Journal of Building Performance Simulation3(4)(2010) 245-254.

[7] S. Kalaiselvam, M. Veerappan, A. Arul Aaron, and S. Iniyan, "Experimental and analytical investigation of solidification and melting characteristics of PCMs inside cylindrical encapsulation," Int. J. Therm. Sci. 47(2008) 858-874.

[8] A. Felix Regin, S.C. Solanki, and J.S. Saini, "Latent heat thermal energy storage using cylindrical capsule: numerical and experimental investigations," Renew. Energy 31(2006) 2025-2041.

[9] K. ElOmari, T. Kousksou, and Y. LeGuer, "Impact of shape of container on natural convection and melting inside enclosures
$\overrightarrow{\mathbf{V}}$ : Velocity vector

Greek Symbols

$\beta$ : Volumetric expansion coefficient $\left(\mathrm{K}^{-1}\right)$

$\Delta \mathrm{H}$ : Latent heat, $\mathrm{J} / \mathrm{kg}$

$\lambda$ : Liquid fraction $(\%)$

$\mu$ : Dynamic viscosity, $\mathrm{kg} / \mathrm{m} . \mathrm{s}$

$\rho$ : Density, $\mathrm{kg} / \mathrm{m}^{3}$

Abbreviations

CFD: Computational Fluid Dynamics

EPCM: Encapsulated Phase Change Material

HTF: Heat Transfer Fluid

LHS: Latent Heat Storage

PCM: Phase Change Material

SHS: Sensible Heat Storage

TES: Thermal Energy Storage

phase change materials," Appl. Therm. Eng. 99(2016) 1212-1224.

used for passive cooling of electronic devices," Appl. Therm. Eng. 31(2011)30223035.

[10] T. Saitoh, and K. Hirose, "High Rayleigh number solutions to problems of latent heat thermal energy storage in a horizontal cylinder capsule,"ASME J. Heat Transf. 104(1982) 545-553.

[11] H. Rieger, U. Projahn, M. Bareiss, and H. Beer, "Heat transfer during melting inside a horizontal tube," ASME J. Heat Transf. 105(1983)226-234.

[12] C.J. Ho, and R. Viskanta, "Heat transfer during inwardmelting in a horizontal tube," Int. J. Heat Mass Transf. 27(1984)705-716.

[13] H.S. Yoo, and S.T. Ro, "Numerical analysis of the phase change processes by coordinate transformations," Trans. KSME 10(1986) 585-592.

[14] A. Prasad, and S. Sengupta, "Nusselt number and melt time correlations for melting inside a horizontal cylinder subjected to an isothermal wall temperature condition," ASME J. Heat Tansf.110(1988) 340-345.

[15] F. Agyenim, N. Hewitt, P. Eames, and M. Smyth, "A review of materials, heat transfer and phase change problem formulation for latent heat thermal energy storage systems (LHTESS)," Renewable and Sustainable Energy Reviews 14(2010) 615-628.

[16] M. Palanisamy, and H. Niyas, "Comparison of thermal characteristics of sensible and latent heat storage materials encapsulatedin different capsule configurations."In: Concentrated Solar Thermal Energy Technologies, pp. 1120, Springer, Singapore, 2018.

[17] B.J. Jones, D. Sun, S. Krishnan, and S.V. Garimella, "Experimental and numerical study of melting in a cylinder," Int. J. Heat Mass Transf.49(2006) 2724-2738. 
Mohamed A. Sultan, Hesham M. Mustafa, Emad A. El-Negiry and Ali M. El-Boz "Effect of Inlet and Geometrical Parameters on the Meltingof PCM Capsules of Elliptical Cross Section”

[18] E. Assis, L. Katsman, G. Ziskind, and R. Letan, "Numerical and experimental study of melting in a spherical shell," Int. J. Heat Mass Transf. 50(2007) 1790-1804.

[19] F.L. Tan, S.F. Hosseinizadeh,J.M. Khodadadi, and L. Fan, "Experimental and computational study of constrained melting of phase change materials (PCM) inside a spherical capsule,"Int. J. Heat Mass Transf. 52(2009)3464-3472.

[20] N. Sharifi, T.L. Bergman, M.J. Allen, and A. Faghri, "Melting and solidification enhancement using a combined heat pipe, foil approach," Int. J. Heat Mass Transf. 78(2014) 930-941.
[21] M.A. Sultan, E.A. El-Negiry, H.M. Mustafa, and A.M. El-Boz, "Experimental and computational study of melting of paraffin wax inside a cylindrical capsules of elliptical cross section," Engineering Research Journal 43(2)(2020) 99-108, Faculty of Engineering, Menoufia University, Egypt.

[22] V.R. Voller, and C. Prakash, "A fixed grid numerical modeling methodology for convection-diffusion mushy region phasechange problems," Int. J. Heat Mass Transf. 30(8)(1987)1709-1719.

[23] V.R. Voller, and C.R. Swaminathan, "General source-based method for solidification phase change," Numer. Heat Transf. Part B Fundam. 19(2)(1991) 175189. 